This dossier has been published on the Global Internet TV Consortium website in March 2021.

\title{
NETFLIX TURKEY DOSSIER
}

By Ece Vitrinel (Galatasaray University) and Aslı Ildır (Koc University)

March 2021

\section{Key Takeaways}

- In Turkey, Netflix made an unambitious entry in an almost-empty VOD scene and in five years has become the major player in an OTT landscape becoming more and more important and fragmented.

- Netflix Turkey's subscribers seem to prefer the platform mostly to keep away from the narrative codes of traditional Turkish TV series with an already established worldwide reputation and demand therefore global quality content.

- New restrictive streaming regulations have not scaled down Netflix's growing investments in Turkey.

- Local services seem more dedicated to catering to Turkish audiences' appetite for 'quality' local content, but Netflix plays a major role in bringing important Turkish productions (mainly popular acquired TV series and mainstream movies) to the world including those produced by its local competitors.

\section{Market}

Netflix launched in Turkey in January 2016. Turkey was one of the 130 countries added to Netflix's operation list at the same time, as part of its major expansion. Netflix did not make any special agreements with internet providers and offered a very limited catalogue, which was especially poor in local content. In an almost-empty video on demand scene where its main competitor was not a local player but piracy, Netflix seemed to aim itself first and foremost at a niche audience of subscribers, cosmopolitan elites living in big cities and already familiar with foreign series and the brand itself.

With a population of 83 million, Turkey has a relatively new but well-established television culture that is almost entirely built upon exportable national TV series, especially melodramas. Television gained importance in Turkish households at a time of great crisis and domestic retreat following the military coup of 1980. The country's TV drama industry has grown exponentially since the 1990s (the years that marked the launch of private TV channels) and has met with broad international success since the mid-2000s. Although some sources claim Turkey as the second-largest exporter of scripted TV content after the U.S., given the lack of reliable export data, it is safer to 
say that the country is among the world's top five exporters of TV programs. At the national level, the average television consumption per day was 4 hours and 21 minutes for 2017 (the highest rate in Europe), and television series represent the most preferred program category. ${ }^{1}$

Turkish productions broadcast on commercial free-to-air TV channels have many distinctive features compared with English-language series. First and foremost, Turkish series range from 120 to 180 minutes in duration, including summaries and advertisements - which is extremely long by international standards. These long durations undoubtedly have a significant impact on the rhythm of the narrative, making Turkish series slow and easy to follow. It is this last feature in particular that has led to their explicit or implicit categorization as 'soap operas' - a genre that is popular across Turkey but which does not attract young, educated, urban viewers. These young city-dwellers constitute the audience base for Netflix, as well as for other local players that seek to distinguish themselves from the commercial broadcasters.

At first, two local OTT services competed alongside Netflix: BluTV, a relatively lowpriced SVOD service and PuhuTV, an AVOD service, both of which launched in 2016, the same year as Netflix. These domestic platforms distinguished themselves from the global streamer by producing successful quality local dramas like Masum (Innocent) (2017), Fi (2017-2018) and Şahsiyet (Persona) (2018), which are said to have 'revolutionized TV in Turkey'. Unlike Turkish broadcast dramas, these originals follow international norms in their duration and number of episodes, with seasons consisting of approximately 8-13 episodes of 45 to 60 minutes each. BluTV and PuhuTV have a strong understanding of the Turkish market and consumer preferences, and - unlike broadcasters - are relatively more free from the restrictions of control/censorship on Turkish television, which has struggled to develop its own premium production model. This difficulty is directly related to the change in TV ratings system in 2012 that resulted in a more conservative audience measurement panel.

Meanwhile, Netflix has tried to solidify its now well-established reputation with the Turkish audience through localized marketing campaigns. The company started first to wink at Turkish audiences with a real cargo ship passing through the Bosporus, carrying the banner 'Love from Colombia' for its mainstream series Narcos (20152017). Local marketing for the Netflix original Bright (2017) showed Orks in Istanbul streets as hairdressers or car repairers drinking Turkish tea. Netflix's campaign for $\underline{L a}$ casa de papel (2017-...) used the same approach. For the promotion of Stranger Things (2016-...), Saadettin Teksoy, an old parodical TV figure was used. All of these advertising campaigns were expensive, high-profile initiatives, suggesting Netflix's awareness of the need for localized promotion strategies tailored to the Turkish market.

Netflix's first Turkish local production The Protector (2018-2020) has been released at the end of 2018. Based on Ottoman and Turkish legends, The Protector tells the story of a superhero who defends his city. The series poster reproduces the famous and cliché image of Istanbul divided by a knife between east and west. Press and social media accounts suggest that the series was better received by foreign audiences than by domestic audiences. 
The Gift (2019-...), Netflix's second Turkish original, is another fantastic serial featuring TV celebrities and historical landmarks such as Cappadocia and Gobeklitepe. The Gift resembles The Protector in its orientalist tone. It was not until the release of Netflix's fourth local original series, the critically acclaimed Ethos in 2020, that Netflix managed to cater to its Turkish audiences' appetite for 'quality' local content. This series built on a much more realistic approach on the divide within the Turkish society revealed that Netflix's audiences in Turkey are not necessarily against the locality but against what is provided them as local. ${ }^{2}$ They are ready to opt for local productions when they are not built on formulas, stereotypes and mystical tales like The Protector and The Gift but on more critical approaches on local issues.

Netflix has been facing increasing regulatory pressure in Turkey. In March 2018, Turkey's parliament approved a law that expands RTÜK's (Turkish radio and TV watchdog authority) control over internet broadcast. According to the new regulation, in September 2019, Netflix--like all the other streaming platforms operating in Turkey--had to apply for a license to continue its domestic operations. This also meant that Netflix has become subject to RTÜK's monitoring processes which operate under some ambiguous principles like the protection of the national and moral values of the society. A Netflix spokesman has said that 'they had not been asked in Turkey to remove any content to that date, nor had they agreed to do so as part of their license application'. But, as will be detailed below, about nine months later, Netflix cancelled the production of a Turkish original, If Only, which featured a gay character. Then Mignonnes (Cuties)--a 2020 French movie known for provoking a trending 'Cancel Netflix' campaign in some countries--was banned from the Netflix Turkey catalogue.

However, these first instances of VOD censorship have not scaled down Netflix's investments in Turkish productions. On the contrary, in 2020 the company announced 14 new 'made in Turkey' productions ( 8 series and 6 movies). At the time of writing, 3 of them have already been released. Netflix also announced that it would open an office in Istanbul in the second half of 2021. In his statement, Netflix Founder and coCEO Reed Hastings said that this decision clearly demonstrates their commitment to Turkey and thanked their more than 3 million members in the country for their support, revealing that Netflix Turkey's subscribers have been doubled in one year (under the pandemic), compared to the previously disclosed figure of 1.5 million subscribers in 2019.

BluTV with 6 million viewers in total until 2020 is the most important other SVOD in Turkey. BluTV has produced so far 26 originals with an understanding of locality which goes well beyond the borders of Istanbul and has the rights of several HBO series as well as many art-house movies from Turkey --in contrast with Netflix's Turkish movie catalogue dominated by mainstream titles. BluTV which operates also in the Middle East, North Africa and Latin America announced on 19 January 2021 a strategic partnership with Discovery. Discovery has become a 35\% shareholder of BluTV which will launch Discovery content on its platform.

Discovery's investment in BluTV shows how Turkey is seen as a potential growth market for VOD. This has also been proven by the statement of Efe Cakarel, Turkish entrepreneur, founder and CEO of MUBI, affirming that their specialized SVOD 
platform has grown 10 times in Turkey in 2020, while their general average growth was 3 times in the world. In September 2020, Amazon Prime Video launched quietly in Turkey with a very competitive price. Mobile phone operators and internet providers have their own integrated services like TV+ and Vodafone TV. A new platform, Gain, is experimenting since the end of 2020 with original, mostly short content designed especially for mobile viewing. The service is intended to be a SVOD but is free for an unknown period. In early 2021 the Turkish media mogul Acun Ilıcalı introduced a new SVOD service named Exxen specialized in reality shows and series.

Turkey still has a very strong traditional television culture and it seems early to say that the dominance of broadcast and cable television has been severely challenged by the late introduction of digital platforms. On the other hand, it is also clear that the OTT scene in the country has completely changed in the last five years following the launch of Netflix Turkey, with the latter becoming more and more important in an over-controlled (in terms of content regulation) yet economically under-supported national film industry. As the slogan of its latest campaign underlines ('Now let them watch with subtitles'), Netflix plays a major role in bringing important Turkish productions to the world including those produced by its local competitors. It is also worth noting that Netflix supported film industry workers in Turkey who have suffered from the Covid-19 pandemic with a fund of 4 million Turkish liras.

\section{Regulation}

Until recently OTT VOD services operating in Turkey were not directly regulated, resulting in an uncensored viewing experience for the local audience. However, the government passed a game-changing law on 21 March 2018 giving permission to the Turkish radio and TV watchdog authority (RTÜK) to regulate and monitor OTT services, effective from 1 August 2019. The law involves not only OTT VOD services but also Internet Protocol television (IPTV) and radio, operating under certain telecommunications networks.

Affected services, including Netflix and Amazon Prime, are now required to obtain a license from RTÜK and pay a license fee in order to operate legally in Turkey. Licenses are given for a 10 -year-period, at a cost of $100 \mathrm{k}$ Turkish liras for video services (\$US14,000).

This law was interpreted as an extension of prior regulatory practices to include OTT services. Regulatory precedents include censorship policies (censoring nudity and sex scenes, blurring cigarette and alcohol use, and beeping strong language) implemented in 2008, following a 2007 law that authorized government to censor the internet, and even temporarily block websites such as Wikipedia and Twitter. A controversial draft law was introduced in 2011 requiring mandatory filters (family, child, domestic, and standard) for ISPs. In 2014 this law came into effect, authorizing Telecommunications Communication Presidency and the Ministry of Transport, Maritime Affairs and Communication to take websites down in 24 hours without a court order. These regulations resulted in the frequent use of VPN, DNS and proxy services in addition to the increase of pirated content in Turkey. ${ }^{3}$ 
One of the alarming consequences of the new RTÜK regulation on streaming platforms is that it provides a suitable environment for censorship and selfcensorship, mainly due to the ambiguous nature of the law and the arbitrary practices of the council. The current RTÜK law works mainly in two ways: by the direct monitoring activities of the council and through the complaints of the audiences. The law includes an article stating that the broadcasters should not violate 'the general morality and the national/spiritual values of the family', which, according to Koçer, paves the way for the law to become an apparatus of the current political agenda that aims for conservative society.

Koçer's concerns proved to be well-founded in 2020, a year that Turkey witnessed multiple instances of censorship and self-censorship. As noted above, a local production, If Only, that Netflix had invested in and planned to distribute was cancelled just before its shooting, due to an 'informal' warning by RTÜK. The showrunner and screenwriter of the series, Ece Yörenç, stated that in order to receive a shooting permission from the Ministry of Culture and Tourism (mandatory for foreign productions), they have been requested to remove the gay character in the story. Even though the crew accepted the request for the series to be produced, Netflix cancelled the show after a private meeting with RTÜK. This move by Netflix has been interpreted as an act of self-censorship (or as an endeavor to protect its international reputation), rather than an 'official' censorship since RTÜK does not have a right to regulate any local/international production before its shooting. Since there is a significant lack of queer/LGBTI+ representation in TV due to regulation, the queer/LGBTI+ content in Netflix's global catalogue has made the platform a target of RTÜK. After the experience with If Only, we could only see an 'implication' of a lesbian couple in Ethos, interpreted as an implicit strategy to parry the RTÜK regulation.

\section{Viewing Habits}

According to The World Bank data, 74 percent of Turkish population, correlating to 62 million, are internet users and according to We Are Social 2020, 93 percent of all users access the internet via smart phones. While definitive data is sparse, a study conducted in January 2020 by online research company DORinsight suggests that smartphones are the second most preferred devices for streaming and most users access audiovisual content via television sets. But mobile devices may not necessarily be out of the streaming game while using a television. Again according to We Are Social 2020, 26 percent of internet users aged 16 to 64 watch content on a TV by casting it from a mobile phone. In the same age group the percentage of internet users who own a device for streaming TV content over the internet is 8.7 percent.

Another important data point, also provided by We Are Social, suggests that 62 percent of internet users aged 16 to 64, watch each month TV content via a streaming subscription service. But it should be noted once more that, related not only to the delay in the introduction of legal platforms and their high costs, but also to the current organization of the audiovisual market and censorship issues, there is a strong culture of piracy in Turkey. With 11.9 billion visits to piracy websites across music, TV, film, publishing and software annually, Turkey ranks fifth in the world for online piracy. While BluTV, a much smaller and local player, makes every effort to protect its 
content against piracy, Netflix has been less aggressive in pursuing enforcement actions in Turkey.

\section{Internet Pricing and Availability}

Turkey is one of the least expensive countries in internet pricing. However, average internet speeds (28.89 Mbps for fixed broadband and 34.79 Mbps for mobile download) are lower than the global average (96.43 Mbps for fixed broadband and 47.20 Mbps for mobile download) according to the latest Speedtest Global Index data. Complaints from Netflix subscribers regarding low quality of streaming, due to connectivity issues, are not uncommon. This is mitigated by the high quality video encoding technology used by Netflix.

There is a significant improvement in both the availability and pricing of internet services in Turkey since Netflix's launch in 2016. Until the beginning of March 2021 the basic Netflix membership plan cost around US $\$ 2.45$ per month, allowing viewing on one device in standard definition. The basic plan could be upgraded to the standard plan (US\$4.17) allowing two devices at a time in high definition. The premium plan on the other hand cost $\$ 5.83$ and allowed for Ultra HD and viewing on four devices at one time. However, Netflix has made a sudden raise in its subscription fees (between 31 to 50 percent) on the $4^{\text {th }}$ of March, drawing a lot of reaction from its subscribers on social media. Currently, the basic plan costs US $\$ 3.58$, the standard plan costs US $\$ 6.62$ and the premium plan costs US\$7.29, which is more expensive compared to the subscription fees of Amazon Prime (\$1.10), MUBI (\$2.78) and BluTV (\$3.18 monthly or $\$ 1.79$ per month for annual subscriptions).

\section{Content}

According to uNoGs, as of January 2021, Netflix Turkey comprises 4880 titles (1770 TV Shows and 3110 movies). Since this size was around 700 titles at the time of its official launch in January 2016, Netflix's Turkey catalogue has grown to around seven times its original size in five years.

Netflix features now a special content collection, 'Made in Turkey', that makes it easier to find Turkish productions. This section in Netflix Turkey currently promotes 217 Turkish titles, 9 of which are local Netflix originals ( 5 series, 3 movies and 1 reality show). Other titles in the Netflix Turkey catalog consist almost exclusively of mainstream Turkish films.

In this sense Netflix's Turkey catalogue mimics the Turkish box-office: both are dominated by domestic blockbusters. Today, Turkey has become one of the rare countries in the world where national films regularly outperform U.S. films in the movie theatres; with its local film market share around 60 percent, Turkey ranks first among European countries. This impressive figure should not over-shadow the fact that the overwhelming majority of national production struggles to survive in a heavily concentrated and monopolized market. And this overview of the Netflix Turkey catalogue proves that Netflix is neither an alternative for these small-scale, independent films to reach an audience that is not necessarily found in theatres. 


\section{Consumers and Press Reaction}

The various media outlets announced Netflix's launch in Turkey with great enthusiasm, mainly due to lack of any substantial SVOD services operating in the country. Even though foreign (mainly American) content was consumed either through cable television or illegal streaming sites, a legal streaming service that did not require any subscription to an ISP or telecommunications company was totally new. However, due to the lack of Turkish dubbing and subtitles, the service was not initially well received by consumers. Over time, Netflix's improved localization of the Turkish service increased its popularity.

Similar to the global market, Netflix became more popular than ever in the past few years, especially after its globalization move in 2016, launching in 130 countries including Turkey. The availability of a large catalogue including titles from worldwide, lack of advertisements or any other disruptions in the flow, the time-shifting options and increased mobility were main factors in users' enthusiasm about the service in Turkey. However, there are also region-specific factors, such as the relatively shorter duration of the series. One of the biggest complaints of audiences in Turkey is the extended duration of the local series, and long ad-breaks, both negatively affecting the quality of the programming. Producers and showrunners are forced to write extended episodes mainly filled with unnecessary details, which also has serious consequences in the workplace, causing extremely long working hours. Therefore, Netflix's allepisode-at-once model with no ad-breaks, shorter durations and 'economic' narratives attracted the viewers in Turkey.

The initial segment of the audience in the early years of Netflix was the youngurbanite internet users (also many 'cord-cutters') who were already used to watching online content. These audiences were pleased about accessing quality content on various technological devices and becoming a part of 'the global audience'. However, together with Netflix's ambitious global expansion and popularization (or mainstreaming) this relatively niche segment of audience started to change, with more users of linear TV subscribing to Netflix. Increased technological literacy and familiarity with VOD were also crucial factors, together with the proliferation of both local and international streaming platforms in Turkey such as Amazon Prime, MUBI, BluTV and PuhuTV. Netflix losing its 'niche' status was a drawback for the former segment of audience, generally criticizing the formulaic narrative structure, predictable plotlines and simplistic characters in the Netflix productions. While Netflix's 'arthouse projects' with auteur directors such as Martin Scorsese and David Fincher were appreciated both by the media and the audience, the general opinion is that Netflix departs from 'quality' as it became more popular.

The discussions on Netflix losing its 'former quality' had been intensified with the launch of Netflix Turkey originals, starting with The Protector. Even though The Protector, as the first Netflix Turkey original, has attracted a lot of attention, widely watched, and was even included in the 'Top 10 in Turkey' section of Netflix, many press accounts and the abovementioned niche segment of the audience were highly critical towards the show, according to the field research/interviews that we conducted. ${ }^{4}$ The series' was generally criticized for its simplistic and formulaic narrative structure. However, the series attracted a lot of global audience, which it 
was intended for in the first place with its orientalist overtones. Netflix positioned itself more in relation to the traditional TV in Turkey, by using globally recognized stars and collaborating with production companies known for their work in local television such as 03 Medya. Netflix's localization strategy of featuring TV stars and collaboration with a production company that offers content for traditional TV clashed with its data-oriented/formulaic narratives, which usually work through genre and aim to reach the global audience. While its main local competitor, BluTV, entered the market with a series that was created by an arthouse director and a critically acclaimed screenwriter, Netflix Turkey's launch was interpreted as a more mainstream move, mainly addressing the global audience. This conflict has caused different reactions and expectations in different segments of the audience mentioned above. While Netflix is increasingly popular in Turkey currently, its changing 'quality' and mainstream content draws criticism from both the audience and press.

\section{Subscriber Estimates}

Netflix is known for not revealing local subscriber numbers. But in September 2019, the day that Netflix applied for a license to continue operating under new broadcasting rules, a Netflix spokesperson announced that they had 1.5 million members in Turkey. This figure appears to have increased since then. As noted above, in December 2020, while announcing plans for a Netflix office in Istanbul, Reed Hastings thanked their more than 3 million members in Turkey for their support. Since many Netflix accounts are used by more than one person, the number of unique Netflix users in Turkey is said to be much higher.

\section{Local Offices}

Netflix Turkey is managed by its Amsterdam headquarters but the company announced recently its plan to open an office in Istanbul in the second half of 2021.

Netflix works with two PR agencies in Turkey: Communication Partner acts as its corporate communication advisor and Golin Istanbul is Netflix's partner for the promotion of its originals.

\footnotetext{
${ }^{1}$ This data from the legal audit institution Television Audience Measurement

${ }^{2}$ It should be noted that Ethos is written and directed by Berkun Oya who had written for BluTV Masum (Innocent)(2017), known as 'the first professional internet TV series of Turkey'. Innocent can also be found in Netflix's catalogue.
}

${ }^{3}$ Bozdağ, C. (2016). Turkey: Coping with Internet Censorship. In: Lobato, R. and Meese, J. (eds), Geoblocking and Global Video Culture. Amsterdam: Institute of Network Cultures, p. 130.

${ }^{4}$ Ildır A. \& Çelik Rappas İ. A. (2021). Netflix in Turkey: Localization and Audience Expectations from Video on Demand (To be published in Convergence). 